\title{
Benign Neonatal Epilepsy
}

National Cancer Institute

\section{Source}

National Cancer Institute. Benign Neonatal Epilepsy. NCI Thesaurus. Code C84593.

An inherited or sporadic disorder characterized by epileptic seizures in the first four to six weeks of life. The seizures tend to subside after the fifteenth week of life. 